\title{
Self-Assembly, Interfacial Nanostructure, and Supramolecular Chirality of the Langmuir-Blodgett Films of Some Schiff Base Derivatives without Alkyl Chain
}

\author{
Tifeng Jiao, ${ }^{1,2}$ Ruirui Xing, ${ }^{1}$ Qingrui Zhang, ${ }^{1}$ Yaopeng Lv, ${ }^{1}$ Jingxin Zhou, ${ }^{1}$ and Faming Gao ${ }^{1}$ \\ ${ }^{1}$ Hebei Key Laboratory of Applied Chemistry, School of Environmental and Chemical Engineering, Yanshan University, Qinhuangdao, \\ Hebei 066004, China \\ ${ }^{2}$ State Key Laboratory of Solid Lubrication, Lanzhou Institute of Chemical Physics, Chinese Academy of Sciences, Lanzhou, \\ Gansu 730000, China
}

Correspondence should be addressed to Tifeng Jiao; tfiao@ysu.edu.cn and Qingrui Zhang; zhangqr@ysu.edu.cn

Received 14 March 2013; Accepted 23 March 2013

Academic Editor: Xingbin Yan

Copyright (C) 2013 Tifeng Jiao et al. This is an open access article distributed under the Creative Commons Attribution License, which permits unrestricted use, distribution, and reproduction in any medium, provided the original work is properly cited.

\begin{abstract}
A special naphthyl-containing Schiff base derivative, $N, N^{\prime}$-bis(2-hydroxy-1-naphthylidene)-1,2-phenylenediamine, was synthesized, and its coordination with various metal ions in situ at the air/water interface has been investigated. Although the ligand contains no alkyl chain, it can be spread on water surface. When metal ions existed in the subphase, an interfacial coordination between the ligand and different metal ions occurred in the spreading film, while different Nanostructures were fabricated in the monolayers. Interestingly to note that among various metal ions, only the in situ coordination-induced $\mathrm{Cu}$ (II)-complex film showed supramolecular chirality, although the multilayer films from the ligand or preformed complex are achiral. The chirality of the in situ $\mathrm{Cu}$ (II)-coordinated Langmuir film was developed due to the special distorted coordination reaction and the spatial limitation at the air/water interface. A possible organization mechanism at the air/water interface was suggested.
\end{abstract}

\section{Introduction}

Supramolecular assemblies of metal complexes are attracting considerable interests owing to their fascinating chemical, thermal, and electrooptical properties [1-6]. The Langmuir and Langmuir-Blodgett (LB) technique provided a sophisticated way to the bottom-up fabrication of the molecular assemblies of metal complex in a controlled way [7, 8]. Generally, there are two approaches to fabricate the interfacial assemblies of metal complexes. One is to use the preformed metal complexes themselves [9-11], and the other is to utilize the in situ coordination reaction between the ligand and the metal ions dissolved in the subphase. While the former is generally used to assembly the ultrathin functional films of metal complexes, the latter method has also proved to be effective [12-20]. In some particular cases, the in situ coordination reaction can induce new interesting properties that preformed metal complex do not have. For example, we have found that some benzimidazole derivatives without alkyl chains or with shorter alkyl chains could be fabricated into organized molecular films through the in situ coordination with $\mathrm{Ag}(\mathrm{I})$, and some new properties were observed [21].

In this paper, we have designed a special Schiff base ligand with the structure shown in Figure 1 based on the following considerations. Firstly, in order to expand the research work to those of special molecules without alkyl chains, we synthesize this ligand and investigate its organized molecular assemblies at the air/water interface. Secondly, aimed at the effect of the spatial hindrance, larger naphthyl group was introduced, and it was placed in different substituted positions around the benzene ring. We found that the ligand could coordinate with various metal ions in situ in the spreading films at the air/water interface and fabricate different nanoarchitectures. Through the in situ coordination, this achiral ligand could form chiral supramolecular assemblies of $\mathrm{Cu}$ (II)-coordinated complex. However, if we spread the preformed $\mathrm{Cu}(\mathrm{II})$-complex on water surface, no chiral molecular assemblies was formed. The chiral monolayers or LB films have been 

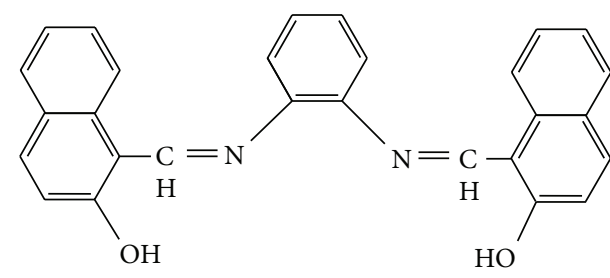

o-NpSB

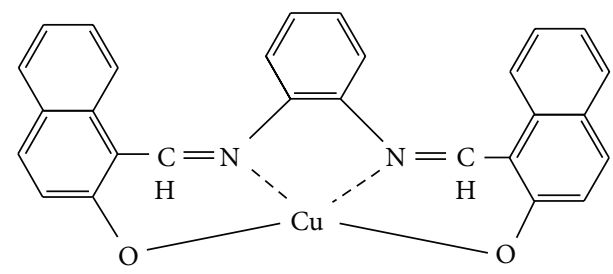

$\mathrm{Cu}(\mathrm{o}-\mathrm{NpSB})$

FIGURE 1: Molecular structures and abbreviations of the Schiff base ligand and its $\mathrm{Cu}(\mathrm{II})$-complex.

reported [22], and we have also reported the chiral assemblies from achiral molecules through the interfacial organization at the air/water interface $[23,24]$. The interfacial coordination and the chirality of the LB films were systematically investigated through a series of characterization methods such as the surface pressure-area $(\pi-A)$ isotherms, UV-Vis spectra, the Fourier transform infrared (FT-IR) spectra, circular dichroism (CD) spectra, and atomic force microscopy (AFM) measurements.

\section{Experimental}

2.1. Materials. 2-hydroxy-1-naphthaldehyde and 1,2-phenylenediamine were obtained commercially from TCI or Aldrich Chemicals and used as received. Various metal salts were obtained from Beijing Chemicals and recrystallized before use. The solvents were obtained from Beijing Chemicals and distilled before use. DMSO- $d_{6}$ was of analytical grade and obtained from Beijing Chemicals. Pure water $(18 \mathrm{M} \cdot \mathrm{cm})$ was obtained from the Milli-Q, Millipore system in all cases. The ligand was synthesized by the condensation of 2-hydroxy-1-naphthaldehyde with the corresponding 0.5 equivalent moles diamines $[25,26]$. Then, the Schiff base ligand, $N, N^{\prime}$-bis(2-hydroxy-1-naphthylidene)-1,2phenylenediamine (abbreviated as o-NpSB) was obtained after recrystallization twice from the anhydrous ethanol. The complex $\mathrm{Cu}(\mathrm{o}-\mathrm{NpSB})$ was prepared according the following procedure: the ligand was dissolved in ethanol, and then the copper acetate solution was added dropwise to the ligand solution, and the solvent was kept in reflux state. Usually, after a few hours, the product separate from the solution and recrystallize twice from the ethanol/chloroform solution and confirmed by ${ }^{1} \mathrm{H}$ NMR and elemental analysis.

2.2. Procedures. Monolayers and the Langmuir-Blodgett films were performed using a KSV minitrough (KSV instruments, Helsinki, Finland). The subphase was prepared by dissolving different metal salts at a concentration of $1.0 \mathrm{mM}$. The monolayer was fabricated by spreading the chloroform solution of amphiphiles onto the air/water interface. After 30 minutes for the completion of coordination reaction and evaporation of solvent, surface pressure-area $(\pi-A)$ isotherms were recorded with a compression speed of $5.0 \mathrm{~mm} / \mathrm{min}$ at $20.0 \pm 0.2^{\circ} \mathrm{C}$. The Langmuir-Blodgett films were prepared by the vertical dipping method at a constant speed of $2.0 \mathrm{~mm} / \mathrm{min}$ on the minitrough. The monolayers were transferred onto freshly cleaved mica plates as a sample for AFM measurement by the vertical dipping method. For the FT-IR, CD, and UV spectra measurements, $\mathrm{CaF}_{2}$ plates and quartz plates were used, respectively.

The monolayer formation and LB film deposition were performed using a KSV minitrough apparatus. FT-IR spectra of the transferred LB films were measured by a JASCO FT/IR660 plus spectrophotometer. UV and CD spectra of the films were obtained by a JASCO UV-530 and a JASCO J-810 CD spectrophotometer, respectively. In the process of measuring CD spectra, the LB film was placed perpendicular to the light path and rotated within the film plane to avoid the polarization-dependent reflections and eliminate the possible angle dependence of the CD signals [27]. AFM images were recorded using tapping mode (Nanoscope IIIa Multimode system, Digital Instruments, Santa Barbara, CA) with silicon nitride cantilever probes. All AFM images were shown in the height mode without any image processing except flattening. MALDI-TOF mass spectra were determined with BIFLEX III. The elemental analysis was carried out with the Flash EA Carlo-Erba-1106 Thermo-Quest. ${ }^{1} \mathrm{H}$-NMR spectra was obtained on an ARX400 (Bruker) NMR spectrometer in DMSO- $d_{6}$ with TMS as an internal standard. The molecular simulation and limiting area calculation was realized by PC Model Version 6.0.

\section{Results and Discussion}

3.1. Complex Film Formation at Air/Aqueous Interface. Figure 2 shows the $\pi$ - $A$ isotherms of o-NpSB on the surfaces of pure water and the solutions containing various metal ions at $20^{\circ} \mathrm{C}$. The isotherm on pure water shows a condensed region with the extrapolated molecular areas of $0.24 \mathrm{~nm}^{2}$ / molecule. Based on the space-filling molecular (CPK) model, o-NpSB can be regarded as a triangle molecule. No matter what side of the triangle attached to the water surface, the estimated limiting molecular areas are between $0.5 \sim 0.7 \mathrm{~nm}^{2} /$ molecule. So, a multilayer film or three-dimensional (3D) structure was suggested to form at the air/water interface. When metal ions existed in the subphase, significant changes were observed. The $\pi$ - $A$ isotherms of o-NpSB on surfaces of the solutions of $\mathrm{Co}^{2+}$ and $\mathrm{Ni}^{2+}$ ions retained the condensed regions, and the shapes of the curves were similar to the case on the water surface. This suggested that most of the o-NpSB may not form a complex with either of these two metal ions. 
As for the other metal ions such as $\mathrm{Pb}^{2+}$ and $\mathrm{Zn}^{2+}$, monolayers with enlarged molecular areas and decreased collapse pressure were obtained. It indicated that the Schiff base ligand and the metal ions might form different coordination complexes in the monolayer. On the subphase containing $\mathrm{Cu}^{2+}$ ions, the isotherm with obvious LE/LC phase transition was obtained. It has a much expanded molecular areas of about $0.31 \mathrm{~nm}^{2} /$ molecule, indicating the formation of a special coordinated film. These differences clearly indicated that the metal ions in the subphase can greatly affect the surface behavior of o-NpSB spreading film.

\subsection{Spectral and Morphological Investigation of Transferred $L B$}

Films. Our previous works have shown that the coordination between the Schiff base ligands and metal ions in the subphase could occur in situ at the air/water interface, which could be monitored by various methods such as UV-Vis and FT-IR spectra. It is clearly observed from Figure 3 that the UV-Vis spectra of o-NpSB LB films fabricated from water surface show the absorption peaks at $232,324,381,465$, and $495 \mathrm{~nm}$, respectively. While the former three peaks could be designated as the $\pi-\pi^{*}$ and $n-\pi^{*}$ transitions for the electrons localized on the azomethine group of the ligand, the latter peaks could be regard as charge transfer transitions [28]. When $\mathrm{Co}^{2+}$ or $\mathrm{Ni}^{2+}$ ions were present in the subphase, only a slight change was observed, indicating the inadequate coordination between the ligand and metal ions. In addition, when $\mathrm{Pb}^{2+}$ or $\mathrm{Cu}^{2+}$ ions were added into the subphase, the obvious spectral change was found, respectively. In comparison with that on water surface, the spectra of $\mathrm{Cu}$ (II)-coordinated films showed peaks at 244, 330,398, 475, and $507 \mathrm{~nm}$, respectively. This change indicated the complete coordination of the Schiff base ligand with copper(II) ion. Moreover, it was interesting to note that there appeared a strong new absorption peak at $418 \mathrm{~nm}$ for the $\mathrm{Zn}$ (II)-coordinated films, which was induced mainly by the different coordination modes between $\mathrm{Zn}$ (II) and other metal ions.

The process of in situ coordination in the LB films can be further verified by the FT-IR spectral measurement. Figure 4 shows the FT-IR spectra in the regions of $1700-1000 \mathrm{~cm}^{-1}$ of 40-layer multilayer films for the Schiff base compound on different subphases. The spectra for $\mathrm{o}-\mathrm{NpSB}$ films from water surface shows characteristic vibration bands centered at 1619 and $1324 \mathrm{~cm}^{-1}$, which can be assigned to $\mathrm{C}=\mathrm{N}$ and phenolic $\mathrm{C}-\mathrm{O}$ stretching vibration, respectively [29]. It is well known that coordination of the Schiff base ligand to the metal ions through the nitrogen atom can reduce the electron density in the azomethine and lower its absorption frequency. On the other hand, phenolic $\mathrm{C}-\mathrm{O}$ stretching band shifted to a higher frequency, indicating coordination through the phenolic oxygen. When on the subphase of $\mathrm{Co}^{2+}$ or $\mathrm{Ni}^{2+}$, there was not obvious change, indicating the slight coordination reaction between ligand with metal ions. This may be attributed to the unsuitable coordination direction caused by the marching modes of different metal ions. In addition, as for the $\mathrm{Zn}(\mathrm{II})$ coordinated films, the characteristic bands shifted to 1610 and $1362 \mathrm{~cm}^{-1}$, respectively. Another obvious change was the strong increment for the peak at $1535 \mathrm{~cm}^{-1}$ due to the change

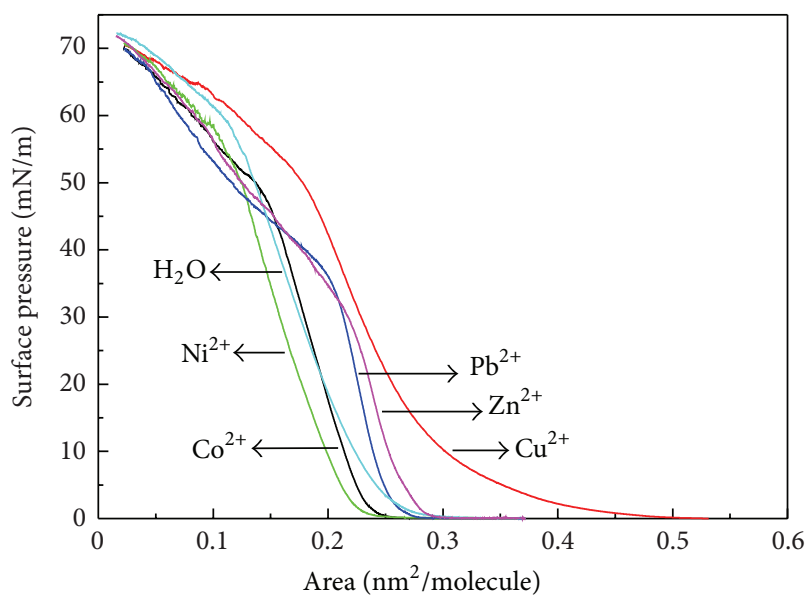

FIGURE 2: Surface pressure-area isotherms of o-NpSB monolayers on pure water and $1.0 \mathrm{mM}$ aqueous solutions of metal salts $\left(\mathrm{Cu}(\mathrm{Ac})_{2}\right.$, $\mathrm{Ni}(\mathrm{Ac})_{2}, \mathrm{Co}(\mathrm{Ac})_{2}, \mathrm{~Pb}(\mathrm{Ac})_{2}$, and $\left.\mathrm{Zn}(\mathrm{Ac})_{2}\right)$.

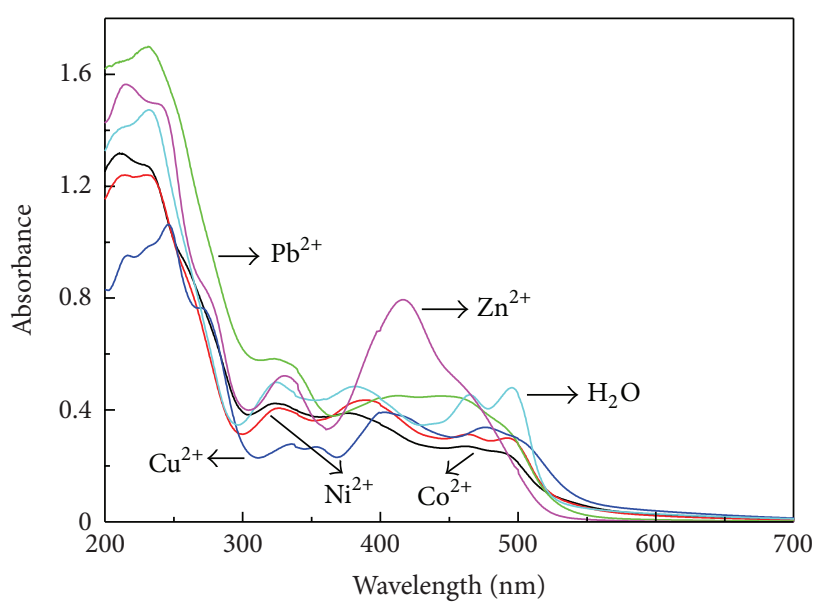

FIgURE 3: UV-Vis spectra of LB films of o-NpSB deposited from water surface and $1.0 \mathrm{mM}$ solution of metal salts onto quartz plates at $20 \mathrm{mN} / \mathrm{m}$.

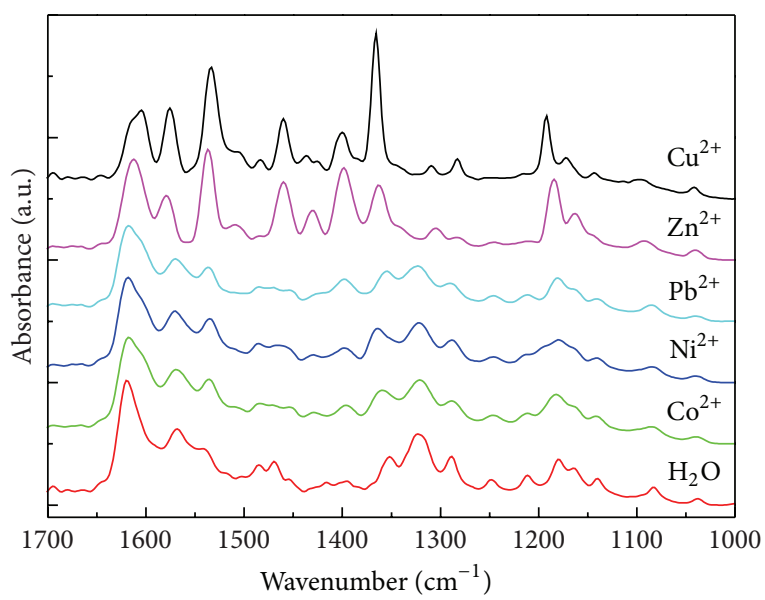

FIGURE 4: FT-IR spectra of LB films of o-NpSB deposited from water surface and $1.0 \mathrm{mM}$ solution of metal salts onto $\mathrm{CaF}_{2}$ plates at $20 \mathrm{mN} / \mathrm{m}$. 

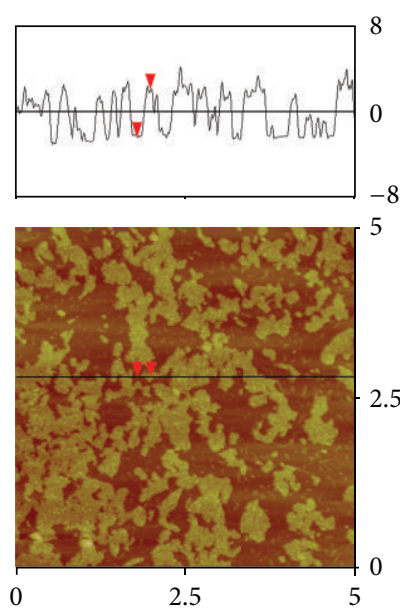

$(\mu \mathrm{m})$

(a)
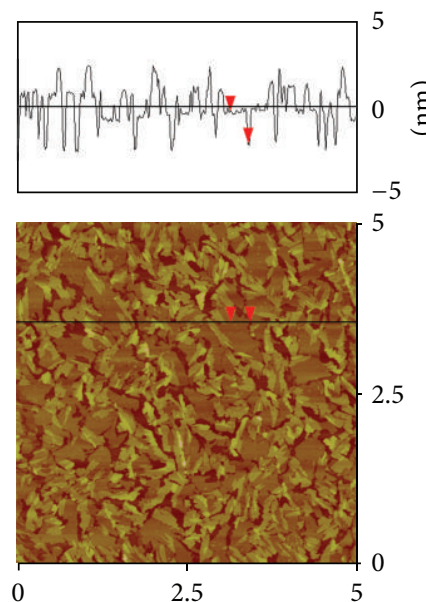

$(\mu \mathrm{m})$
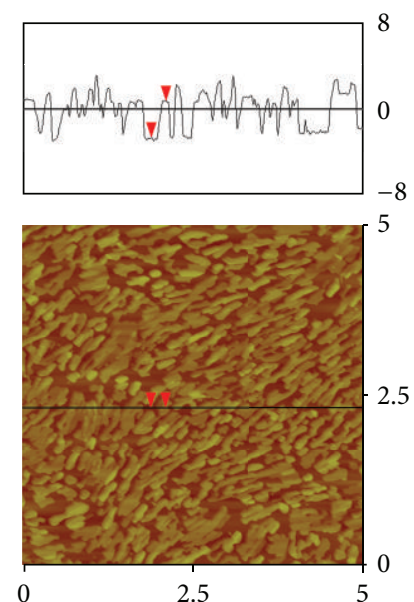

$(\mu \mathrm{m})$

(b)
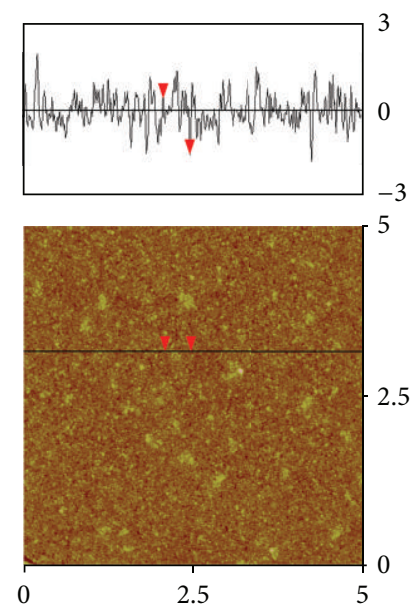

$(\mu \mathrm{m})$
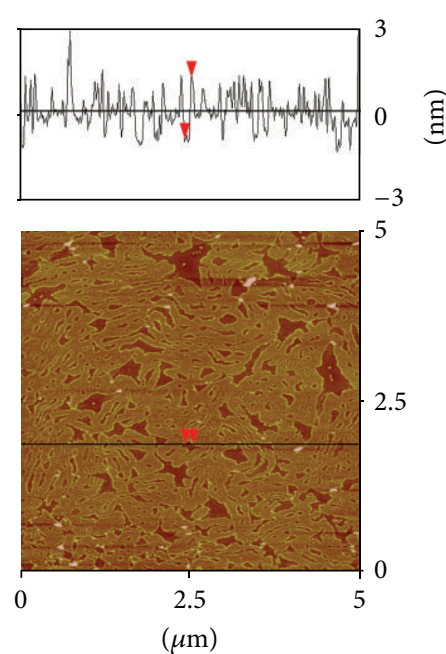

(c)
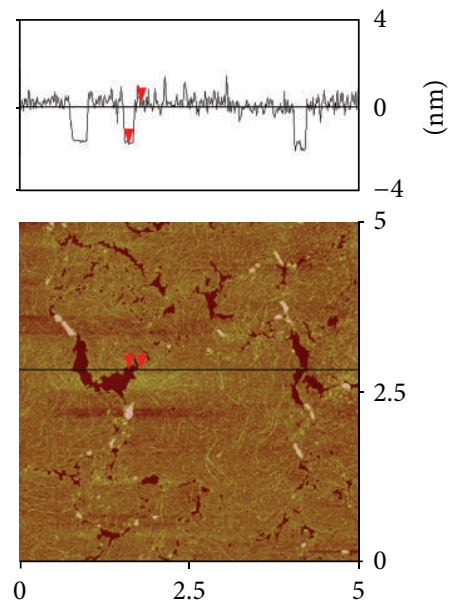

( $\mu \mathrm{m})$

FIGURE 5: AFM pictures of LB films of o-NpSB deposited from water surface (a) and $1.0 \mathrm{mM}$ metal salts solution transferred at $20 \mathrm{mN} / \mathrm{m}$ : (b) $\mathrm{Cu}^{2+}$ ions; (c) $\mathrm{Co}^{2+}$ ions; (d) $\mathrm{Ni}^{2+}$ ions; (e) $\mathrm{Pb}^{2+}$ ions; (f) $\mathrm{Zn}^{2+}$ ions.

of aromatic moiety. It indicated the complete coordination occur at the air/water interface. Similar spectral change with a little shift was observed for the $\mathrm{Cu}(\mathrm{II})$-coordinated films, suggesting the different coordination mode for $\mathrm{Cu}(\mathrm{II})$ in comparison with $\mathrm{Zn}(\mathrm{II})$ ions.

To get further insight into the assembly mode of the Schiff base amphiphile at air/water interface, one layer of the spreading films was transferred onto a newly cleaved mica surface, and their surface morphologies were measured with AFM, as shown in Figure 5. For o-NpSB on the pure water surface, larger irregular domains composed of dotted aggregates could be clearly observed in Figure 5(a). Through the section analysis, it was obtained that the domains have an average height of about $4.3 \pm 0.2 \mathrm{~nm}$. When $\mathrm{Cu}$ (II) ions were present in the subphase, blocks-like domains with the averaged height of $4.6 \mathrm{~nm}$ were observed. Based on the CPK model, these values corresponded to 3 or 2 layers of the molecular thickness, which confirmed that the smaller molecular areas in the $\pi$-A isotherms were due to the multilayer formation at the air/water interface. Furthermore, we observed the different morphologies such as slices, collapsed film, dense packing dots, and porous film appeared on other metal ions subphases, which may be due to the different coordination modes between the Schiff base ligand and metal ions. So, it indicated that metal ions indeed play an important role in regulating and modulating the interfacial morphology and assembly mode. Now, the study for coordination compounds or coordination polymers nanomaterials is a rising field in materials research [30,31]. The present work may give some new clue to design and prepare coordination compounds with special nanostructures.

3.3. Characterization of Chiral Supramolecular Assembly in LB Films. Figure 6(a) shows the UV-Vis spectra of the transferred films both from water and the subphase containing $\mathrm{Cu}(\mathrm{II})$ ions. A clear spectral change was observed for both 


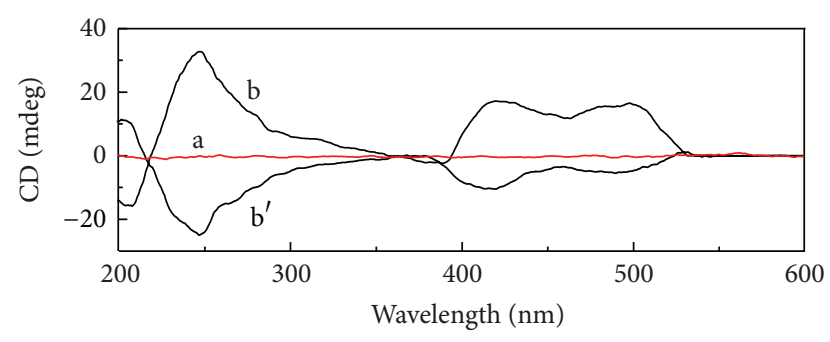

(A)

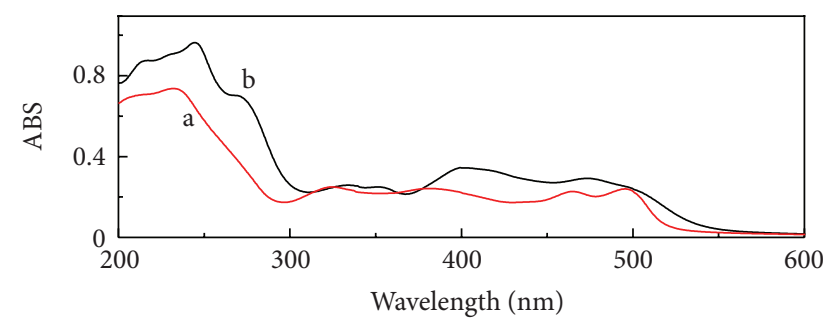

(B)

FIGURE 6: UV-Vis (A) and circular dichroism (CD) (B) spectra of 40layer o-NpSB LB films transferred from pure water surface (a) and $1.0 \mathrm{mM}$ aqueous $\mathrm{Cu}(\mathrm{Ac})_{2}$ subphase $\left(\mathrm{b}\right.$ and $\mathrm{b}^{\prime}$ represent the spectra for the film fabricated in different batches).

the cases, indicating the coordination of the Schiff base ligand with $\mathrm{Cu}$ (II) ion. It is interesting to note that the in situ $\mathrm{Cu}$ (II)coordinated o-NpSB film showed strong cotton effect in the CD spectra, as shown in Figure 6(b). The cotton effect consisted of an intense excitation couplet at 248, 420, and $499 \mathrm{~nm}$, with a crossover at $219 \mathrm{~nm}$. Since the cotton effect appeared almost in the same position as those in the absorption spectrum, it can be suggested that CD signal originated from the interaction between the $\mathrm{Cu}$ (II)-complex themselves. Interestingly, if we spread the preformed complex $\mathrm{Cu}(\mathrm{o}-\mathrm{NpSB})$ on water surface, no CD signal could be detected for the transferred film, although these two kinds of films showed the same UV-Vis spectra. In addition, for the in situ $\mathrm{Cu}(\mathrm{II})$ coordinated film, the CD signals could be opposite in different fabrication batches, although the sign of CD signal is the same everywhere in one batch. This phenomenon is essentially the same as those reported by our group, indicating that the macroscopic chirality might be formed by a stereoregular stacking of the molecules [24]. The in situ Cu(II)-coordinated ligand film was different from the preformed complex film, which suggested that there existed a subtle packing differences.

In our present work, it is found that the chiral supramolecular assembly could be fabricated when the ligand o$\mathrm{NpSB}$ was spread onto aqueous $\mathrm{Cu}$ (II) ions subphase. Since $\mathrm{Cu}$ (II) ions can penetrate into the LB film, the ex situ coordinating process between the o-NpSB film from water surface and $\mathrm{Cu}$ (II) ions in solution was tried to verify if similar chiral film could be constructed, which could be monitored by the UV and FT-IR spectra. Of course this may be another way to fabricate the coordination LB films.
Figure 7 shows the UV spectral changes of the o-NpSB LB films fabricated from the pure water surface after immersion in an aqueous solution of $10.0 \mathrm{mM} \mathrm{Cu}(\mathrm{Ac})_{2}$ at time intervals of $10,20,60,110,130,190$, and 240 minutes, respectively. The significant changes in the spectra are the absorption peak at $211,232,324,381,465$, and $495 \mathrm{~nm}$ shifted to $217,244,330,398$, 475 , and $507 \mathrm{~nm}$, respectively. Simultaneously, the new peaks appeared at 270 and $357 \mathrm{~nm}$. In addition, in the UV spectra of in situ $\mathrm{Cu}$ (II)-coordinated o-NpSB LB films and $\mathrm{Cu}(\mathrm{o}-\mathrm{NpSB})$ LB films fabricated from pure water, the peaks at 324 and $381 \mathrm{~nm}$ even shifted to 334 and $402 \mathrm{~nm}$, respectively. In general, the final UV spectrum is very similar to that of the LB films deposited from the $\mathrm{Cu}$ (II) ions subphase or the corresponding complex $\mathrm{Cu}(\mathrm{o}-\mathrm{NpSB}) \mathrm{LB}$ films fabricated from pure water interface. This result indicated that the coordination can also progress between the o-NpSB LB film and $\mathrm{Cu}$ (II) ions by immersing it into the aqueous solution of $\mathrm{Cu}(\mathrm{Ac})_{2}$. Using this technique, we could control the incorporation of $\mathrm{Cu}$ (II) ions into the LB film. However, the final ex situ $\mathrm{Cu}$ (II)coordinated films show no chiral signal, which suggested this type of complex film was different from the in situ coordinated films in the view of assembly mode.

The progress of ex situ coordination in the LB film can be further verified by the FT-IR spectral measurement. Figure 8 shows the FT-IR spectra of a 40 -layer o-NpSB LB films before and after immersion in aqueous solutions of $10.0 \mathrm{mM}$ $\mathrm{Cu}(\mathrm{Ac})_{2}$. In the region of $1700-1000 \mathrm{~cm}^{-1}$, the spectrum prior to immersion shows characteristic vibration bands at 1211 , $1248,1324,1541,1568$, and $1619 \mathrm{~cm}^{-1}$. After immersing the film into $\mathrm{Cu}(\mathrm{Ac})_{2}$ solution, the bands at 1211 and $1248 \mathrm{~cm}^{-1}$ disappeared, while the bands at 1324, 1541, 1568, and $1619 \mathrm{~cm}^{-1}$ shifted to $1366,1534,1576$, and $1604 \mathrm{~cm}^{-1}$, respectively. Further, the bands above increased their intensity with the increasing immersion time. These changes of vibrational band indicated the coordination between $\mathrm{Cu}$ (II) ions with ligand o-NpSB. It is interesting to note that we have not seen any change or appearance of a band around $1660 \mathrm{~cm}^{-1}$, which can be assigned to the $\mathrm{CH}_{3} \mathrm{COO}^{-}$anion. This indicates that only $\mathrm{Cu}(\mathrm{II})$ ions were incorporated into the LB film. In addition, we have measured the FT-IR spectra of the LB film deposited from the o-NpSB monolayer on aqueous subphases containing $\mathrm{Cu}(\mathrm{Ac})_{2}$ and the corresponding complex $\mathrm{Cu}(\mathrm{o}-$ NpSB) LB films fabricated from pure water interface. The final spectrum is the same as the above two spectra, indicating that a similar reaction occurred in the LB film and in the solution. It should be noted that by dissolving the in situ $\mathrm{Cu}(\mathrm{II})$ coordinated films into chloroform and measured their TOFMS, a 1:1 (ligand: $\mathrm{Cu}$ ) complex was confirmed. These results indicated that the molecular structure of the in situ formed $\mathrm{Cu}(\mathrm{II})$-complex is essentially the same as the preformed one in solution.

From the results of UV-Vis and FT-IR spectra, it is clear that the in/ex situ complex films were similar except that the in situ $\mathrm{Cu}$ (II)-coordinated films show chiral signal. To further clarify this difference, AFM measurement was performed for both cases, as shown in Figure 9. It is easily observed from the pictures of $\mathrm{o}-\mathrm{NpSB}$ LB film transferred from $\mathrm{Cu}(\mathrm{II})$ ions subphase that regular block-shaped domains with the averaged height of $4.6 \mathrm{~nm}$ could be obtained. When 


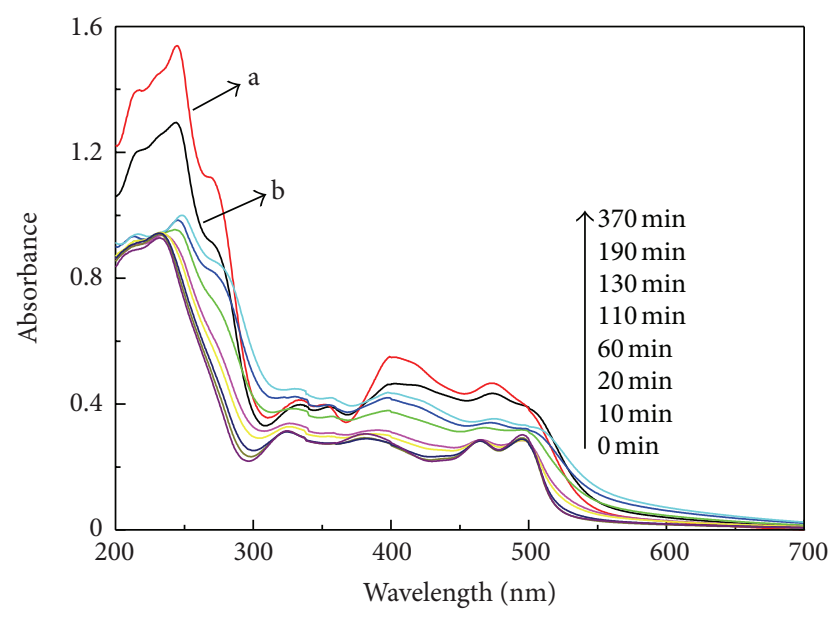

FIgURE 7: UV-Vis spectra of a 40-layer o-NpSB LB films before and after immersion in $10.0 \mathrm{mM} \mathrm{Cu}(\mathrm{Ac})_{2}$ solution at different time intervals. The line (a) represents the spectrum of a 60-layer complex $\mathrm{Cu}(\mathrm{o}-\mathrm{NpSB}) \mathrm{LB}$ films fabricated from pure water interface. The line (b) represents the spectrum of a 50-layer o-NpSB LB films fabricated from $1.0 \mathrm{mM}$ aqueous $\mathrm{Cu}(\mathrm{Ac})_{2}$ subphase.

the preformed $\mathrm{Cu}(\mathrm{II})$-complex was spread on water surface, morphologies of noodle-like fibers were obtained. The fibers can be extended to nearly one micrometer and with a width of approximately $32 \pm 5 \mathrm{~nm}$. However, an analysis on the section profile revealed that the average height for the preformed one was $3.1 \mathrm{~nm}$. Based on the CPK model, it suggested that these values correspond to three or two molecular thickness, which confirmed that the smaller molecular areas in the $\pi$ $A$ isotherms were due to the multilayer formation at the air/ water interface, which was observed in several spread films [32-34].

3.4. Discussion of Assembly Mode in LB Films. The above interesting results of the supramolecular chirality and the differences in the morphologies of the in situ $\mathrm{Cu}(\mathrm{II})$-coordinated ligand film and the preformed complex films can be possibly explained as illustrated in Figure 10. The o-NpSB molecule was regarded as a triangle molecule in which three hydrophobic phenyl and naphthyl groups occupied the corners and sides of the triangle. The hydrophilic hydroxyl groups and the imine groups localized in the two sides of molecular skeleton, as shown in Figure 10(a). Once oNpSB was spread on water surface, these hydrophilic parts will predominantly orient to the water surface. When spreading on the subphase containing $\mathrm{Cu}(\mathrm{II})$ ion, an in situ coordination occurred between $\mathrm{Cu}(\mathrm{II})$ ion and the two hydrophilic groups. During this in situ coordination process with $\mathrm{Cu}(\mathrm{II})$, the two hydrophilic parts together with the hydrophobic naphthyl groups were forced to be near the water surface, as shown in Figure 10(b). Due to this coordination and spatial hindrance, the long side of the triangle molecule would contact with the water surface, and the adjacent molecules are suggested to align cooperatively in a helical sense, as shown in Figure 10(c). Although both the left- and right-handed helical sense will

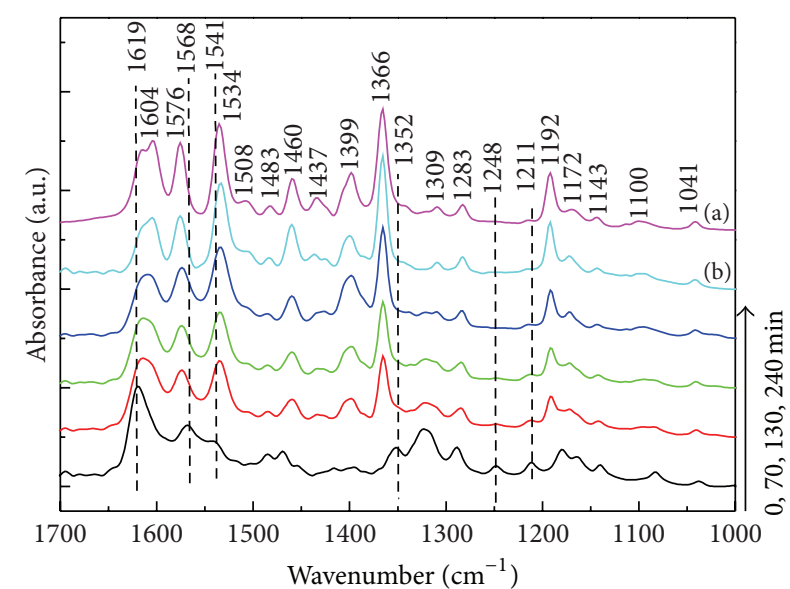

FIGURE 8: FT-IR spectra of 60-layer o-NpSB LB films before and after immersion in $10.0 \mathrm{mM} \mathrm{Cu}(\mathrm{Ac})_{2}$ solution at different time intervals. The line (a) represents the spectrum of a 60-layer complex $\mathrm{Cu}(\mathrm{o}-$ NpSB) LB films fabricated from pure water interface. The line (b) represents the spectrum of a 50-layer o-NpSB LB films fabricated from $1.0 \mathrm{mM}$ aqueous $\mathrm{Cu}(\mathrm{Ac})_{2}$ subphase.

occur due to the confinement of a two-dimensional platform, one kind of the helical sense could possibly be predominant, and thus we got a macroscopic chirality of the complex films. In the case of preformed $\mathrm{Cu}(\mathrm{o}-\mathrm{NpSB})$, the situation was different. The hydrophilic part of the complex was encapsulated in the center, while each side of the triangle molecules is hydrophobic, as expressed in Figure 10(d). When spreading on water surface, each of hydrophobic side could be near the water surface, as shown in Figure 10(e). This caused the random stacking of the $\mathrm{Cu}(\mathrm{o}-\mathrm{NpSB})$ molecules on water. In this case, the triangular complex molecule could not stack cooperatively, and no macroscopic chirality could be obtained. This is partially verified in the AFM. In the case of in situ $\mathrm{Cu}(\mathrm{II})$ coordinated ligand film, a flat block was formed. In contrast, the spreading preformed complex film showed larger surface roughness.

It should be noted that the preformed $\mathrm{Cu}(\mathrm{o}-\mathrm{NpSB})$ molecule itself was achiral. We obtained the single crystal of the preformed $\mathrm{Cu}(\mathrm{o}-\mathrm{NpSB})$ and confirmed that complex molecule was achiral through the $\mathrm{X}$-ray diffraction. In addition, it should be further noted that although the ligand of o-NpSB could form complexes with other metal ions such as $\mathrm{Zn}$ (II), $\mathrm{Ni}(\mathrm{II})$, and $\mathrm{Co}(\mathrm{II})$, no chirality was detected in those complex films. This might be related to the different stereo packing structures of the metal complexes. In addition, these results will expand the research areas for the special amphiphiles without alkyl chain and give some clues to prepare new nanomaterials and nanocomposites [35-38].

\section{Conclusions}

In this paper, a special nonchain Schiff base ligand was found to be spreadable on water surface and the aqueous subphase containing metal ions. The in situ coordination between 


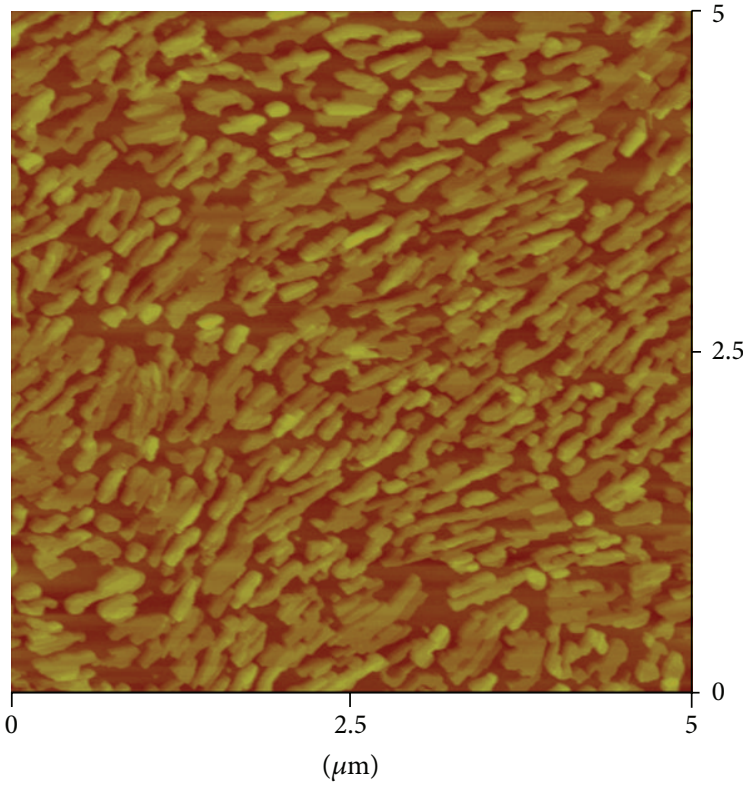

(a)

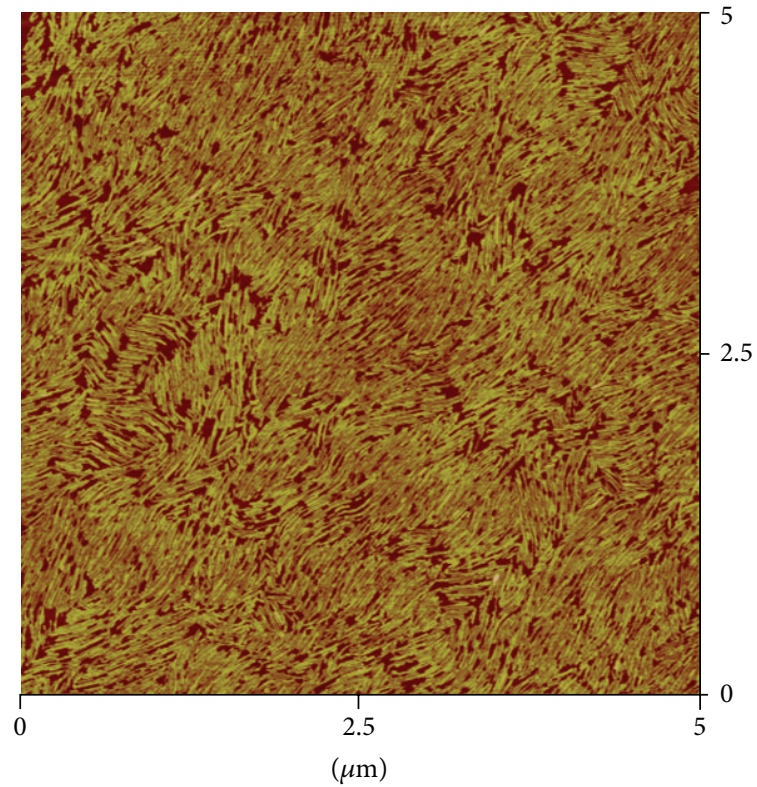

(b)

Figure 9: AFM pictures of the one-layer in situ $\mathrm{Cu}(\mathrm{II})$-coordinated o-NpSB LB film deposited on $\mathrm{Cu}(\mathrm{II})$ ions subphase (a) and the complex $\mathrm{Cu}(\mathrm{o}-\mathrm{NpSB}) \mathrm{LB}$ film fabricated on water surface (b) at a surface pressure of $15 \mathrm{mN} / \mathrm{m}$, respectively.

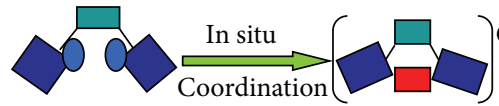

(a)

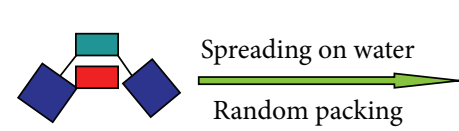

(d)

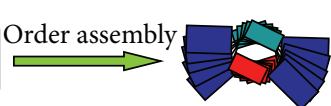

(c)

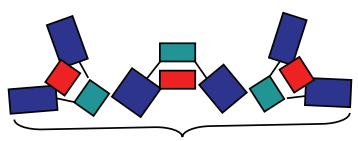

(e)

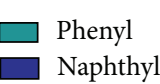

Hydrophilic part

$\square$ Complexed with $\mathrm{Cu}(\mathrm{II})$

FIgURE 10: A possible schematic illustration on the formation of the chiral assemblies: (a) ligand molecule; (b) in situ $\mathrm{Cu}$ (II)-coordinated complex; (c) stacked in a helical sense to form chiral assembly: the stacking direction of the molecules are from the top of the paper to inside; (d) preformed $\mathrm{Cu}(\mathrm{o}-\mathrm{NpSB})$; (e) stacked in a random way. For the sake of clarity, only one layer was shown in the Scheme. A multilayer film formation was supposed in the spreading film, which could be regarded as the superposition of the illustrated monolayers.

the ligand and different metal ions can fabricate various nanoarchitectures at the air/water interface due to the different matching modes. In addition, only the in situ $\mathrm{Cu}(\mathrm{II})$ coordinated ligand film showed a supramolecular chirality, although the ligand was achiral. However, no supramolecular chirality was obtained for the spreading film from preformed $\mathrm{Cu}(\mathrm{II})$-complex. A possible mechanism related to the hydrophilicity, hydrophobicity, and the stereo-cooperative stacking of the ligand and its $\mathrm{Cu}(\mathrm{II})$-complex was proposed to explain the formation of the supramolecular chirality.
Those results will expand the research areas for the special amphiphiles without alkyl chain and open an important way to the design and fabrication of chiral molecular assemblies from achiral molecules.

\section{Acknowledgments}

This work was financially supported by the National Natural Science Foundation of China (Grant nos. 20903078 and 21207112), the Natural Science Foundation of Hebei Province (Grant nos. B2012203060 and B2013203108), the China Postdoctoral Science Foundation (Grant nos. 2011M500540 and 2012M510770), the Support Program for Hundred Excellent Innovation Talents from Universities and Colleges of HebeiProvince (Grant no. CPRC020), the Science Foundation for the Excellent Youth Scholars from Universities and Colleges of Hebei Province (Grantno. Y2011113), the Scientific Research Foundation for Returned Overseas Chinese Scholars of Hebei Province (Grant no. 2011052), and the Open Foundation of State Key Laboratory of Solid Lubrication (Lanzhou Institute of Chemical Physics, CAS) (Grant no. 1002).

\section{References}

[1] B. Tieke, "Coordinative supramolecular assembly of electrochromic thin films," Current Opinion in Colloid \& Interface Science, vol. 16, no. 6, pp. 499-507, 2011.

[2] M. Schulz, M. Karnahl, M. Schwalbe, and J. G. Vos, "The role of the bridging ligand in photocatalytic supramolecular assemblies for the reduction of protons and carbon dioxide," Coordination Chemistry Reviews, vol. 256, no. 15-16, pp. 1682-1705, 
2012.

[3] C. P. Myers and M. E. Williams, "Directed self-assembly of inorganic redox complexes with artificial peptide scaffolds," Coordination Chemistry Reviews, vol. 254, no. 19-20, pp. 2416-2428, 2010.

[4] P. Zabierowski, J. Szklarzewicz, K. Kurpiewska, K. Lewiński, and W. Nitek, "Assemblies of substituted salicylidene-2-ethanolamine copper(II) complexes: from square planar monomeric to octahedral polymeric halogen analogues," Polyhedron, vol. 49, no. 1, pp. 74-83, 2013.

[5] P. P. Chakrabarty, D. Biswas, S. García-Granda, A. D. Jana, and S. Saha, "Sodium ion assisted molecular self-assembly in a class of Schiff-base copper(II) complexes," Polyhedron, vol. 35, no. 1, pp. 108-115, 2012.

[6] J. V. D. Gucht, E. Spruijt, M. Lemmers, and M. A. Cohen Stuart, "Polyelectrolyte complexes: bulk phases and colloidal systems," Journal of Colloid and Interface Science, vol. 361, no. 2, pp. 407422, 2011.

[7] S. Reuter, E. Amado, K. Busse et al., "Formation of 2D spherulites in Langmuir films of amphiphilic T-shaped liquid crystals," Journal of Colloid and Interface Science, vol. 372, no. 1, pp. 192-201, 2012.

[8] N. C. M. Zanon, O. N. Oliveira Jr, and L. Caseli, "Immbolization of uricase enzyme in Langmuir and Langmuir-Blodgett films of fatty acids: possible use as a uric acid sensor," Journal of Colloid and Interface Science, vol. 373, no. 1, pp. 69-74, 2012.

[9] K. Wohnrath, C. J. L. Constantino, P. A. Antunes et al., "Molecularly organized Langmuir-Blodgett films from a ruthenium biphosphine complex," Journal of Physical Chemistry B, vol. 109, no. 11, pp. 4959-4964, 2005.

[10] G. Hemakanthi and A. Dhathathreyan, "Synthesis of nickel sulfide using Langmuir-Blodgett films of nickel complex of 2-hydroxy-5-nitro-N-benzylidene hexadecylamine monolayers at air/water interface," Chemical Physics Letters, vol. 334, no. 4-6, pp. 245-249, 2001.

[11] A. Aoki, Y. Abe, and T. Miyashita, "Effective photoinduced electron transfer in hetero-deposited redox polymer LB films," Langmuir, vol. 15, no. 4, pp. 1463-1469, 1999.

[12] S. Zhang, H. L. Wang, M. Chen, and D. J. Qian, "Monolayers and Langmuir-Blodgett films of $\mathrm{Fe}^{2+}$-mediated polyelectrolyte with viologen derivatives as linkers at the air-water interface," Colloids and Surfaces A, vol. 384, no. 1-3, pp. 561-569, 2011.

[13] J. Nagel, U. Oertel, P. Friedel, H. Komber, and D. Mobius, "Langmuir-Blodgett layers from Schiff base copper(II) complexes," Langmuir, vol. 13, no. 17, pp. 4693-4698, 1997.

[14] S. S. Sundari, A. Dhathathreyan, M. Kanthimathi, and B. U. Nair, "Langmuir-Blodgett films of Schiff base complexes of copper(II)," Langmuir, vol. 13, no. 18, pp. 4923-4925, 1997.

[15] R. Vijayalakshmi, A. Dhathathreyan, M. Kanthimathi, V. Subramanian, B. U. Nair, and T. Ramasami, "Penetration of DNA into mixed monolayers of 1,3-bis(salicylideneamino)propanechromium(III) perchlorate and octadecylamine at an air/water interface," Langmuir, vol. 15, no. 8, pp. 2898-2900, 1999.

[16] Y. Q. Liang, Z. Q. Zhang, L. X. Wu, Y. C. Tian, and H. D. Chen, "Structure control of synthetic bilayer membranes from singlechain amphiphiles containing the Schiff base segment: II. pH and temperature dependence of the aggregational behaviors," Journal of Colloid and Interface Science, vol. 178, no. 2, pp. 714$719,1996$.

[17] F. P. Fugisawa, A. P. Ramos, P. C. de Sousa Filho, O. A. Serra, and M. E. D. Zaniquelli, "Formation of thin luminescent
$\mathrm{Eu}^{3+}$-LB films by in situ coordination with 2, 3, 5, 6-tetra $\left(2^{\prime}\right.$ pyridyl)pyrazine and 1-octadecanol in pure and mixed Langmuir monolayers," Journal of Luminescence, vol. 132, no. 5, pp. 1116-1121, 2012.

[18] T. Jiao, C. Cheng, F. Xi, and M. Liu, "Metal ion modulated ultrathin films and nanostructures of tyrosine-based bolaamphiphile at the air/water interface," Thin Solid Films, vol. 503, no. 1-2, pp. 230-235, 2006.

[19] Y. Q. Liang, L. X. Wu, Y. C. Tian, Z. Q. Zhang, and H. D. Chen, "Structure control of synthetic bilayer membranes from singlechain amphiphiles containing the Schiff base segment: I. Conformation control and spectral characterization," Journal of Colloid and Interface Science, vol. 178, no. 2, pp. 703-713, 1996.

[20] T. Jiao, X. Li, Q. Zhang et al., "Interfacial assembly of a series of trigonal Schiff base amphiphiles in organized molecular films," Colloids and Surfaces A, vol. 407, pp. 108-115, 2012.

[21] H. Gong, M. Yin, and M. Liu, “in situ coordination-induced Langmuir film formation of water-soluble 2,5-dimercapto1,3,4-thiadiazole at the air/water interface and the growth of metal sulfide nanostructures in their templated LangmuirSchaefer films," Langmuir, vol. 19, no. 20, pp. 8280-8286, 2003.

[22] K. Okamoto, M. Taniguchi, M. Takahashi, and A. Yamagishi, "Studies on energy transfer from chiral polypyridyl $\mathrm{Ru}(\mathrm{II})$ to Os(II) complexes in cast and Langmuir-Blodgett films," Langmuir, vol. 17, no. 1, pp. 195-201, 2001.

[23] J. Yuan and M. Liu, "Chiral molecular assemblies from a novel achiral amphiphilic 2-(heptadecyl) naphtha[2,3]imidazole through interfacial coordination," Journal of the American Chemical Society, vol. 125, no. 17, pp. 5051-5056, 2003.

[24] P. Guo and M. Liu, "Fabrication of chiral Langmuir-Schaefer films of achiral amphiphilic Schiff base derivatives through an interfacial organization," Langmuir, vol. 21, no. 8, pp. 3410-3412, 2005.

[25] Z. Popović, V. Roje, G. Pavlović, D. Matković-Čalogović, and G. Giester, "The first example of coexistence of the ketoaminoenolimino forms of diamine Schiff base naphthaldimine parts: the crystal and molecular structure of $N, N$-bis(1-naphthaldimine)-o-phenylenediamine chloroform (1/1) solvate at $200 \mathrm{~K}$," Journal of Molecular Structure, vol. 597, no. 1-3, pp. 39-47, 2001.

[26] T. Jiao and M. Liu, "Phase behaviors and 2D-3D morphological transition of aromatic Schiff base derivatives in organized molecular films," Acta Physico-Chimica Sinica, vol. 28, no. 6, pp. 1418-1424, 2012.

[27] C. Spitz, S. Dähne, A. Quart, and H. W. Abraham, "Proof of chirality of J-aggregates spontaneously and enantioselectively generated from achiral dyes," Journal of Physical Chemistry B, vol. 104, no. 36, pp. 8664-8669, 2000.

[28] K. Chichak, U. Jacquemard, and N. R. Branda, "The construction of (salophen)ruthenium(II) assemblies using axial coordination," European Journal of Inorganic Chemistry, vol. 2002, no. 2, pp. 357-368, 2002.

[29] K. N. Kumar and R. Ramesh, "Synthesis, luminescent, redox and catalytic properties of $\mathrm{Ru}$ (II) carbonyl complexes containing $2 \mathrm{~N}_{2} \mathrm{O}$ donors," Polyhedron, vol. 24 , no. 14, pp. 1885-1892, 2005.

[30] S. J. Musevi, E. Şahin, and A. Aslani, "Synthesis of PbO and $\mathrm{PbBr}_{2}$ nanopowders from nano-sized 2D lead(II) coordination polymers," Powder Technology, vol. 229, pp. 30-36, 2012.

[31] Y. Zheng, N. Guo, Y. Jia, H. Qiao, and H. You, "From big to small: a general strategy of converting lanthanide coordination polymers to oxide and hydroxide nanoparticles," Inorganic Chemistry Communications, vol. 20, pp. 225-227, 2012. 
[32] I. Weissbuch, S. Guo, R. Edgar et al., "Oriented crystalline thin films of tetracosanedioic acid and its metal salts at the airaqueous solution interface," Advanced Materials, vol. 10, no. 2, pp. 117-121, 1998.

[33] I. Weissbuch, P. N. W. Baxter, S. Cohen et al., "Self-assembly at the air-water interface. In-situ preparation of thin films of metal ion grid architectures," Journal of the American Chemical Society, vol. 120, no. 19, pp. 4850-4860, 1998.

[34] Y. Zhang, R. Jin, L. Zhang, and M. Liu, "Growth of $\mathrm{CaCO}_{3}$ in the templated Langmuir-Blodgett film of a bolaamphiphilic diacid," New Journal of Chemistry, vol. 28, no. 5, pp. 614-617, 2004.

[35] J. Varshosaz, F. Hassanzadeh, H. Sadeghi, F. Firozian, and M. Mirian, "Effect of molecular weight and molar ratio of dextran on self-assembly of dextran stearate polymeric micelles as nanocarriers for etoposide," Journal of Nanomaterials, vol. 2012, Article ID 265657, 10 pages, 2012.

[36] Y. Shu, G. Ou, L. Wang, J. Zou, and Q. Li, "Surface modification of titanium with heparin-chitosan multilayers via layer-by-layer self-assembly technique," Journal of Nanomaterials, vol. 2011, Article ID 423686, 8 pages, 2011.

[37] W. Kong, C. Chen, K. Mai, X. Shi, R. Hu, and Z. Wang, "Largescale synthesis and selfassembly of monodisperse spherical $\mathrm{TiO}_{2}$ nanocrystals," Journal of Nanomaterials, vol. 2011, Article ID 526246, 4 pages, 2011.

[38] J. Lu, I. Do, H. Fukushima, I. Lee, and L. T. Drzal, "Stable aqueous suspension and self-assembly of graphite nanoplatelets coated with various polyelectrolytes," Journal of Nanomaterials, vol. 2010, Article ID 186486, 11 pages, 2010. 

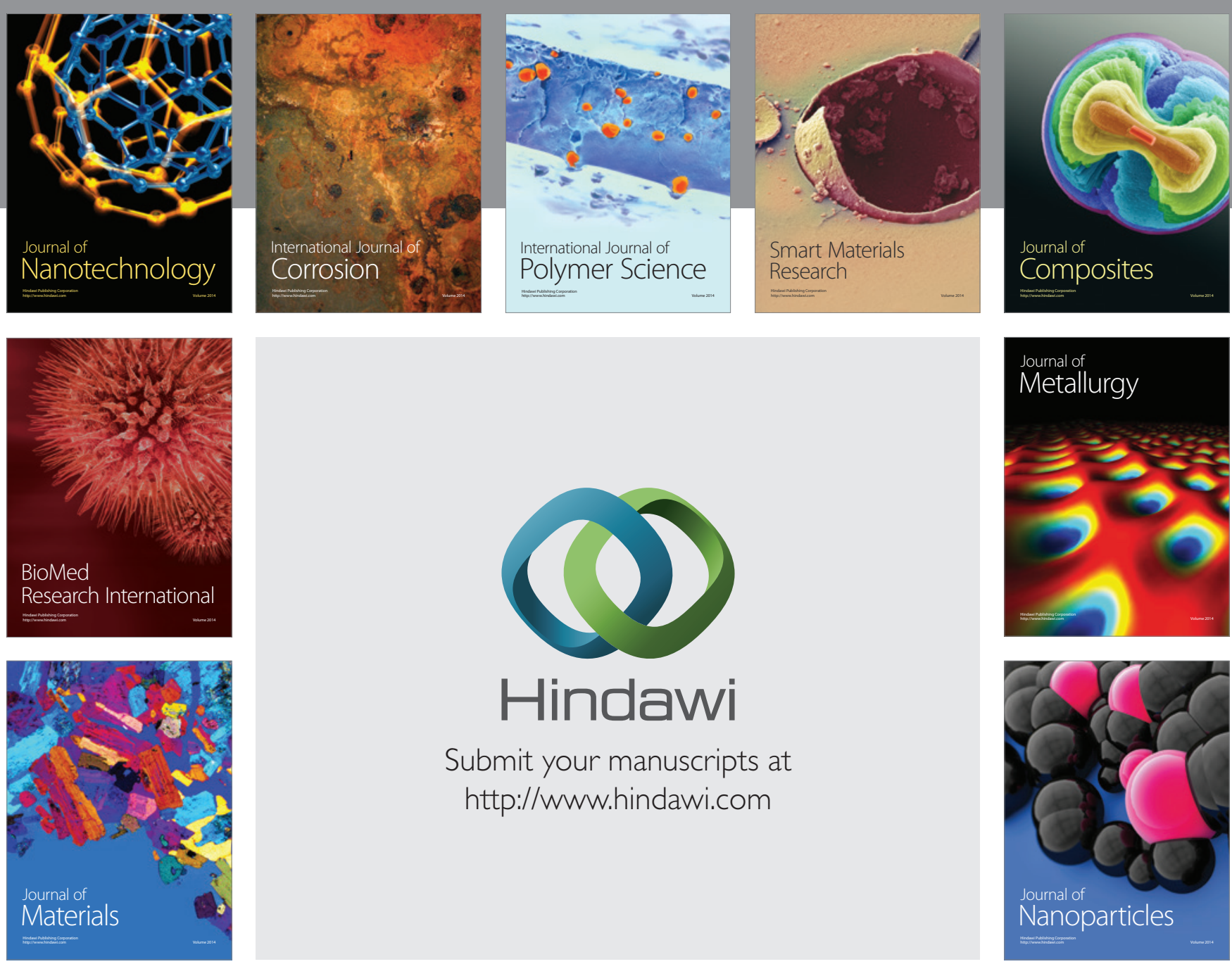

Submit your manuscripts at http://www.hindawi.com
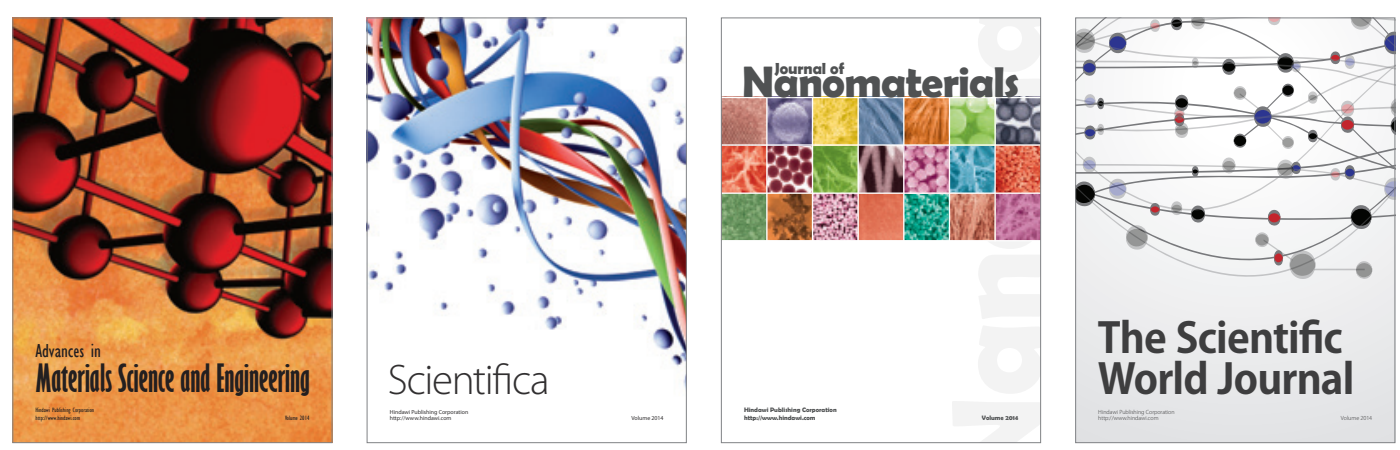

\section{The Scientific World Journal}
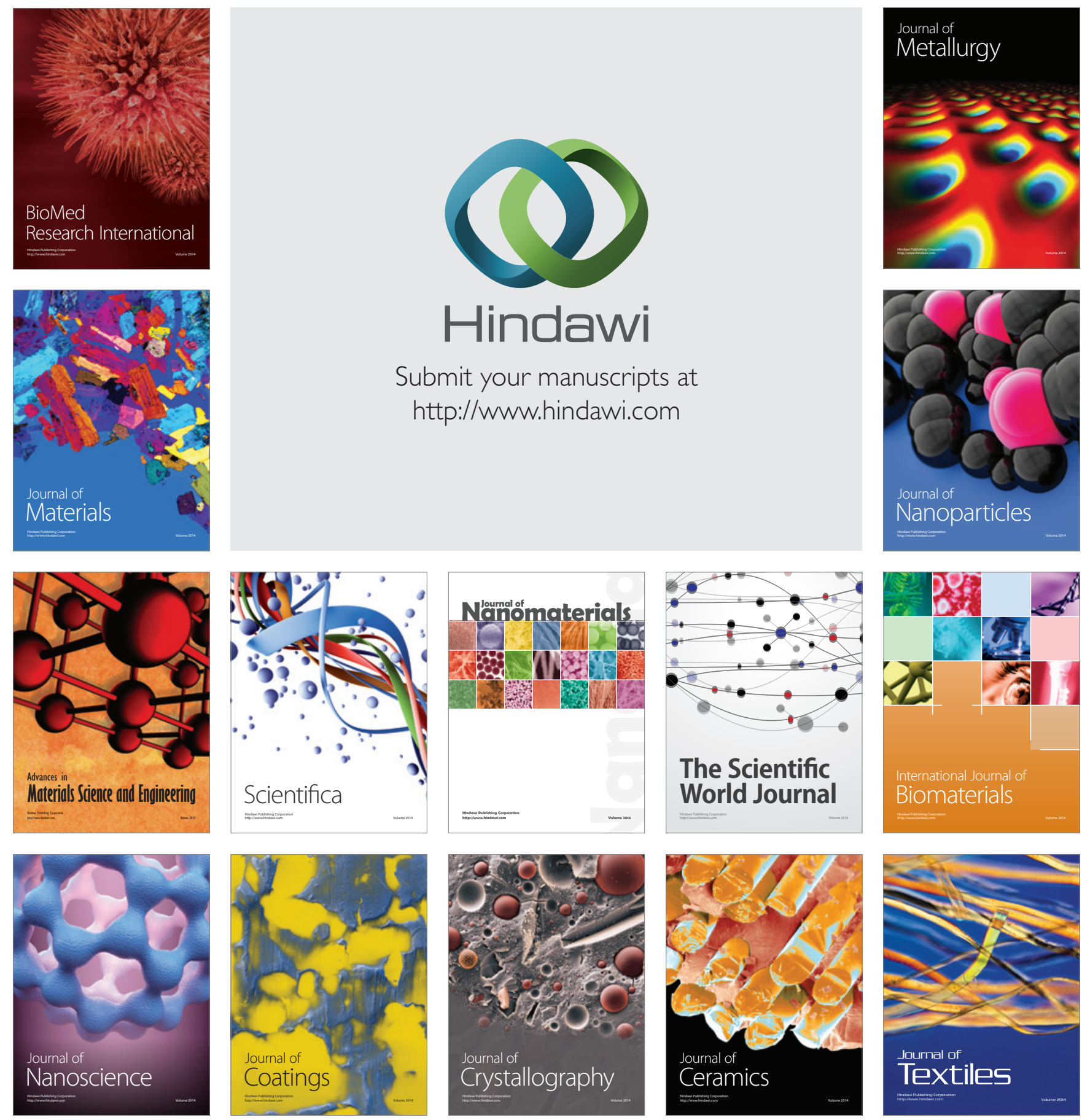